University of Nebraska - Lincoln

DigitalCommons@University of Nebraska - Lincoln

Faculty Publications from the Department of Electrical \& Computer Engineering, Department Electrical and Computer Engineering

2011

\title{
A Current-Sensorless MPPT Quasi-Double-Boost Converter for PV Systems
}

\author{
Christopher J. Lohmeier \\ University of Nebraska-Lincoln, chris929@huskers.unl.edu \\ Jianwu Zeng \\ University of Nebraska-Lincoln, jzeng@huskers.unl.edu \\ Wei Qiao \\ University of Nebraska-Lincoln, wqiao@engr.unl.edu \\ Liyan Qu \\ University of Nebraska-Lincoln, lqu2@unl.edu \\ Jerry L. Hudgins \\ University of Nebraska-Lincoln, jhudgins2@unl.edu
}

Follow this and additional works at: https://digitalcommons.unl.edu/electricalengineeringfacpub

Part of the Electrical and Computer Engineering Commons

Lohmeier, Christopher J.; Zeng, Jianwu; Qiao, Wei; Qu, Liyan; and Hudgins, Jerry L., "A Current-Sensorless MPPT Quasi-Double-Boost Converter for PV Systems" (2011). Faculty Publications from the Department of Electrical and Computer Engineering. 207.

https://digitalcommons.unl.edu/electricalengineeringfacpub/207

This Article is brought to you for free and open access by the Electrical \& Computer Engineering, Department of at DigitalCommons@University of Nebraska - Lincoln. It has been accepted for inclusion in Faculty Publications from the Department of Electrical and Computer Engineering by an authorized administrator of DigitalCommons@University of Nebraska - Lincoln. 


\title{
A Current-Sensorless MPPT Quasi-Double-Boost Converter for PV Systems
}

\author{
Christopher Lohmeier, Jianwu Zeng, Wei Qiao", Liyan Qu, and Jerry Hudgins \\ Department of Electrical Engineering \\ University of Nebraska-Lincoln \\ Lincoln, NE, 68588-0511 USA \\ chris929@huskers.unl.edu; jzeng@huskers.unl.edu; wqiao@engr.unl.edu; liyanqu@ieee.org; jhudgins2@unl.edu
}

\begin{abstract}
This paper proposes a current-sensorless maximum power point tracking (MPPT) quasi-double-boost converter for photovoltaic (PV) systems. Instead of using sensors, the output current of the PV system is obtained from the measured voltage ripple in the input capacitor of the DC-DC converter. The estimated current is used by a hill-climbing (HC) MPPT algorithm to determine the optimal duty ratio for controlling the DC-DC converter. The operating principle, theoretical analysis, and design guidelines of the quasi-double-boost converter are provided in the paper. Simulation studies are carried out in MATLAB Simulink by using real solar radiation data obtained from the National Renewable Energy Laboratory (NREL); results show that the proposed system and control algorithm work effectively for current-sensorless MPPT control of the PV systems. Experimental results for a real PV system are provided to further validate the simulation of the quasi-double boost converter and testify the effectiveness of the current-sensorless MPPT control algorithm.
\end{abstract}

\section{INTRODUCTION}

In recent years, there has been an increasing interest of using Photovoltaic (PV) systems to supply electricity for various consumers due to their many merits, such as cleanness and no noise. But the output power of a PV system is largely determined by the solar irradiation and the temperature. At a certain weather condition, the output power of a PV system depends on the terminal voltage of the system. To maximize the power output of PV systems, a high-efficiency, low-cost DC-DC converter with an appropriate maximum power point tracking (MPPT) control algorithm is commonly employed to maintain the terminal voltage of the PV system at optimal values in various solar

This material is based upon work supported by the Federal Highway Administration under Agreement No. DTFH61-10-H-00003. Any opinions, findings, and conclusions or recommendations expressed in this publication are those of the authors and do not necessarily reflect the view of the Federal Highway Administration. radiation conditions 0 .

Although, various MPPT methods [2]-[5] have been proposed in existing literature, the commonly used MPPT algorithms are the power based methods, which include the hill-climbing (HC) [2] method, perturb-and-observe (P\&O) method [3], and the incremental conductance (IncCond) [4] method. The HC and P\&O methods achieve the same fundamental thought in different ways 0 . These two methods are widely applied because their simplicity; however, they can fail under rapidly changing atmospheric conditions. The IncCond algorithm can track the maximum power point more accurately than the $\mathrm{HC}$ and $\mathrm{P} \& \mathrm{O}$ methods; however, it is relatively complicated to implement. All of these three methods require measurement of both current and voltage from the solar panel for power calculations of the PV system.

Since the current of the solar panel is related with the terminal voltage, it is possible to estimate the current from the voltage. Such a current-sensorless MPPT technique is able to reduce the number of sensors used for the PV system. In [6], the current information was estimated from other known variables based on an assumption that the input current of the boost DC-DC converter reaches zero during the power detecting interval, which requires a power detecting cycle and to measure voltage with high a sample rate. Similarly, the current was estimated from the voltage ripple in a flyback inverter [7].

In many applications, a high boost ratio is required for the DC-DC converter to connect the low-voltage PV panel to a relatively high-voltage load or power grid. This cannot be satisfied by using basic DC-DC boost converters. This paper proposes a new current-sensorless MPPT for PV systems, where a quasi-double-boost converter [8] is employed as the interface between the PV panel and the load or power grid to provide a high boost ratio and extended control range compared to the basic boost converter. In the proposed control, the steady-state current of the PV system is 


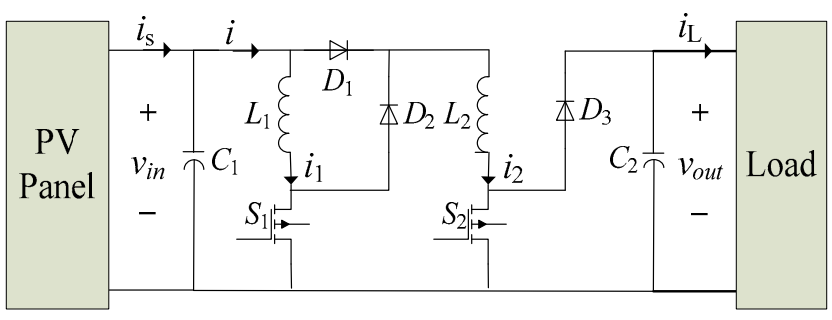

Fig. 1. Configuration of the PV system.

estimated from the voltage ripple of the input capacitor of the converter. The estimated current is then used with the measured voltage of the PV panel to determine the output power for the MPPT control of the PV system, without the need for the information of solar radiation. Furthermore, an electrical circuit model is proposed to accurately model the dynamics of PV panels. Simulation studies are carried out in MATLAB Simulink by using real solar radiation data obtained from the NREL to validate the proposed system and control algorithm. Experiments are performed for a real PV system to further validate the simulation results and testify the effectiveness of the proposed current-sensorless MPPT.

\section{THE PV SYSTEM}

The PV system consists of a PV panel and a DC/DC converter. Fig. 1 shows the configuration of the PV system, in which a quasi-double boost converter is used to connect between the PV panel and the load.

\section{A. PV Panel Model}

A dynamic PV panel model shown in Fig. 2(a) is proposed for simulation purpose, where $i_{s}$ is the output current of the PV panel; $i_{p h}$ is the photocurrent; $R_{S}$ is the equivalent series resistance of the PV panel. The model can be expressed as:

$$
\begin{aligned}
& i_{s}=i_{p h}-i_{s a t}(T)\left[e^{q\left(v_{i n}+i_{s} R_{S}\right) / k T A}-1\right] \\
& i_{s a t}(T)=i_{s a t}\left(T_{r e f}\right) e^{K_{S}\left(T-T_{r e f}\right)} \\
& i_{p h}=\left[I_{S C}+K_{i}\left(T-T_{r e f}\right)\right] \lambda
\end{aligned}
$$

where $T$ and $T_{r e f}(=298 \mathrm{~K})$ are the measured and reference temperatures, respectively; $i_{\text {sat }}(T)$ is the saturation current at $T ; q\left(=1.6 \times 10^{-19}\right)$ is the charge of an electron; $A$ is the ideal factor of a PN junction; $k\left(=1.38 \times 10^{-23} \mathrm{~J} / \mathrm{K}\right)$ is the

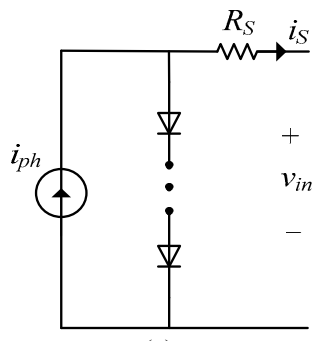

(a)

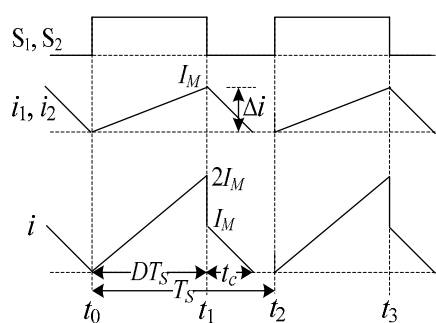

(b)
Fig. 2. (a) The PV panel model; (b) current waveforms in the DCM.
Boltzmann's constant; $i_{s a t}\left(T_{r e f}\right)$ is the reference saturation current at $T_{r e f} ; K_{s}\left(\approx 0.072 /{ }^{\circ} \mathrm{C}\right)$ is the temperature coefficient; $I_{S C}$ is the short circuit current at $1 \mathrm{~kW} / \mathrm{m}^{2} ; K_{i}\left(=3 \mathrm{~mA} /{ }^{\circ} \mathrm{C}\right)$ is the temperature coefficient; and $\lambda$ is the solar isolation in $\mathrm{kW} / \mathrm{m}^{2}$.

\section{B. Quasi-Double Boost Converter}

A quasi-double-boost converter [8] is used due to the requirement of a high voltage regulation ratio (200/28). As shown in Fig. 1, the double-boost DC/DC converter consists of two inductors. The boost function is achieved by switching two switches simultaneously. However, the following analysis reveals that the voltage regulation ratio is not exactly double boost derived in [8].

The converter can work in a continuous current mode (CCM) or a discontinuous current mode (DCM). The DCM is studied since the CCM is a special case of the DCM. The waveforms in the DCM are shown in Fig. 2(b), where $S_{1}$ and $S_{2}$ are the gate signals of the two switches; $T_{S}$ and $D$ are the switching period and duty ratio of the DC-DC converter, respectively; $t_{\mathrm{c}}$ is the duration that the inductor currents decrease to zero from the maximum value; and $I_{M}$ is the maximum inductor current. Neglect the ripples of $v_{\text {in }}$ and $v_{\text {out }}$, the following formula can be obtained for switch on and off periods, respectively.

$$
\begin{aligned}
& I_{M}=\frac{V_{\text {in }} D T_{S}}{L} \\
& V_{\text {in }}-V_{\text {out }}=-2 L \frac{I_{M}}{t_{c}}
\end{aligned}
$$

where $L_{1}=L_{2}=L ; V_{\text {in }}$ and $V_{\text {out }}$ are the average values of $v_{\text {in }}$ and $v_{\text {out }}$, respectively. Then the voltage regulation ratio can be obtained from (4) and (5) as follows.

$$
\frac{V_{\text {out }}}{V_{\text {in }}}=\frac{2 D T+t_{c}}{t_{c}}
$$

The average value of the input current $i$ in a period can be calculated as:

$$
I=\left(D+\frac{t_{c}}{2 T_{S}}\right) I_{M}
$$

According to the power conservation law, $V_{\text {in }} I=P_{\text {out }}$, then

$$
\frac{V_{\text {out }} \times V_{\text {out }}}{R}=V_{\text {in }}\left(D+\frac{t_{c}}{2 T_{S}}\right) I_{M}
$$

where $R$ is equivalent resistance of the load. Substitute (4) and (7) into (8), then

$$
\frac{D+\frac{t_{c}}{2 T_{S}}}{\frac{t_{c}}{2 T_{S}} \times \frac{t_{c}}{2 T_{S}}}=\frac{D \cdot T_{S} \cdot R}{L}
$$




$$
t_{c}=\frac{1+\sqrt{1+4 D^{2} T_{S}\left(\frac{R}{L}\right)}}{D\left(\frac{R}{L}\right)}
$$

Equation (10) indicates that the conduction time during the switch off period is related with $R, L, T$ and $D$. The following formula can be obtained by substituting (10) into (6).

$$
\frac{V_{\text {out }}}{V_{\text {in }}}=\frac{1+\sqrt{1+4 D^{2} T_{S}\left(\frac{R}{L}\right)}}{2}
$$

Equation (11) indicates that in the DCM mode, the voltage ratio is not only determined by the duty ratio, but also determined by the output current and the inductance value. If the equivalent load resistance varies from time to time, the duty ratio should be changed to sustain the desired voltage gain.

When $t_{\mathrm{c}}=(1-D) T_{\mathrm{S}}$, the converter works in the critical mode, substitute $t_{\mathrm{c}}$ into (9), then the critical inductance $L_{C}$ is:

$$
L_{C}=\frac{D(1-D)^{2}}{(1+D)} \cdot \frac{R T_{S}}{2}
$$

Equation (1) indicates that the critical inductance depends on the duty cycle and load. Equation (1) also indicates that there exist a supremum (i.e., the least upper bound) value $L_{\mathrm{M}}$ such that for any $L>L_{\mathrm{M}}$, the circuit work in the CCM mode for any duty ratios. This unique maximal critical inductance can be derived by setting the first derivative of $L_{C}$ with respect to $D$ as zero.

$$
\frac{\partial L_{C}}{\partial D}=0
$$

Then

$$
L_{M}=0.113 \cdot \frac{R T}{2}
$$

Therefore, (14) can be used to design the inductor so that the circuit always works in the CCM mode when the load is fixed. On the other hand, if the inductance is fixed, then there exists a critical duty cycle $\left(D_{C}\right)$, when $D<D_{C}$, the converter works in the DCM; otherwise, it works in the $\mathrm{CCM}$, in which (6) can be further simplified as:

$$
\frac{V_{\text {out }}}{V_{\text {in }}}=\frac{1+D}{1-D}
$$

Equation (15) indicates that the voltage regulation ratio is not simply twice that of the basic boost converter as claimed in [8]. Thus, the original double-boost converter named in [8] is called the quasi-double-boost converter in this paper.

\section{THE CURRENT-SENSORLESS MPPT CONTROL}

The proposed current-sensorless method utilizes the voltage ripple of the input capacitor to estimate the output current of the PV panel. Fig. 3 shows the waveforms of the voltage $v_{i n}$ and currents $i_{1}$ and $i$ (see Fig. 1) in a period in the $\mathrm{CCM}$, where $I_{\mathrm{m}}$ denotes the minimal value of the inductor current. Suppose the circuit works in the CCM at all times. In the steady state, the average current that flows through two inductors in a period is:

$$
I=\frac{I_{m}+I_{M}}{2}(1+D)
$$

In $\left[t_{0}, t_{1}\right]$, the energy stored in the two inductors is provided by the PV panel and the capacitor $C_{1}$, then

$$
\frac{1}{2} C_{1}\left[v_{i n}^{2}\left(t_{1}\right)-v_{i n}^{2}\left(t_{0}\right)\right]+V_{i n} \cdot I \cdot D \cdot T_{S}=2 \cdot \frac{1}{2} \cdot L\left(I_{M}^{2}-I_{m}^{2}\right)
$$

where $V_{i n}=\frac{v_{i n}\left(t_{0}\right)+v_{i n}\left(t_{1}\right)}{2}$ is the average voltage of the input capacitor $C_{1} ; \Delta V_{i n}=v_{i n}\left(t_{0}\right)-v_{i n}\left(t_{1}\right)$ is the voltage ripple of the input capacitor. Then the average value of the current $i$ in Fig. 3 can be estimated as:

$$
I_{\text {esm }}=\frac{(1+D) \cdot C_{1} \cdot \Delta V_{\text {in }}}{D(1-D) T_{\mathrm{S}}}
$$

Equation (18) indicates that the output current of the PV panel can be estimated from the duty ratio and voltage ripple of the input capacitor, which can be calculated by the voltages sampled at the time $t_{0}$ and $t_{1}$. By setting $I_{m}=0$, then the current in the DCM can be written as:

$$
I_{\mathrm{esm}}=\frac{\left(D+\frac{t_{\mathrm{C}}}{2 T_{\mathrm{S}}}\right) \cdot C_{1} \cdot \Delta V_{\mathrm{in}}}{\left(1-D-\frac{t_{\mathrm{C}}}{2 T_{\mathrm{S}}}\right) D T_{\mathrm{S}}}
$$

The relationship between $\Delta V_{\text {in }}$ and $d V$ is $\Delta V_{\text {in }} \approx 2 \cdot d V$, where $d V$ is the difference value between $V_{\max }$ and $V_{\text {in }}$ (see Fig. 3). Fig. 4 shows the ripple detection schematics. By properly design the parameters; the amplified voltage ripple $d V$ can be obtained by sampling the voltage at time $t_{0}$. Once the current is obtained, the output power of the PV panel can be estimated as $P=V_{i n} \cdot I_{e s m}$. Fig. 5 illustrates the
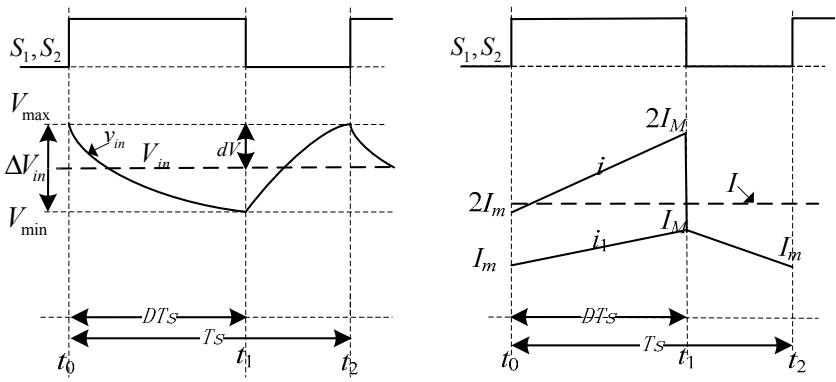

Fig. 3. Voltage and current waveforms in the CCM. 
current-sensorless hill-climbing MPPT.

\section{Simulation Results}

Simulation studies are carried out in Matlab Simulink to validate the proposed current-sensorless MPPT quasidouble-boost converter for a PV system. The system parameters are set as follows: the open-circuit voltage and short-circuit current of the 175-W PV panel (BP SX 3175)

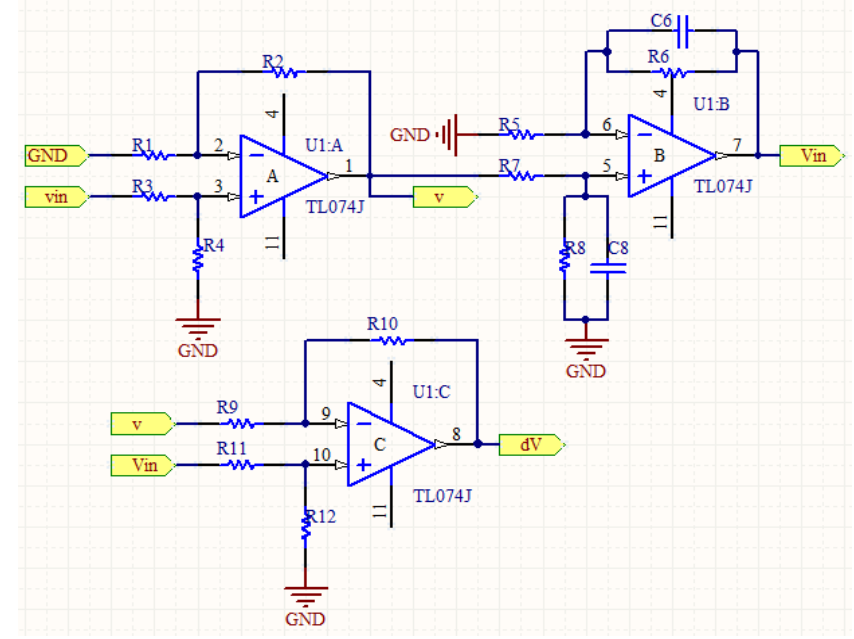

Fig. 4. The schematic of the sampling circuit for voltage ripple detection.

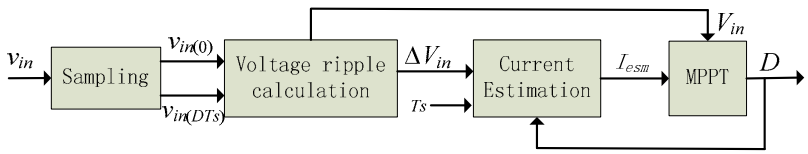

(a)

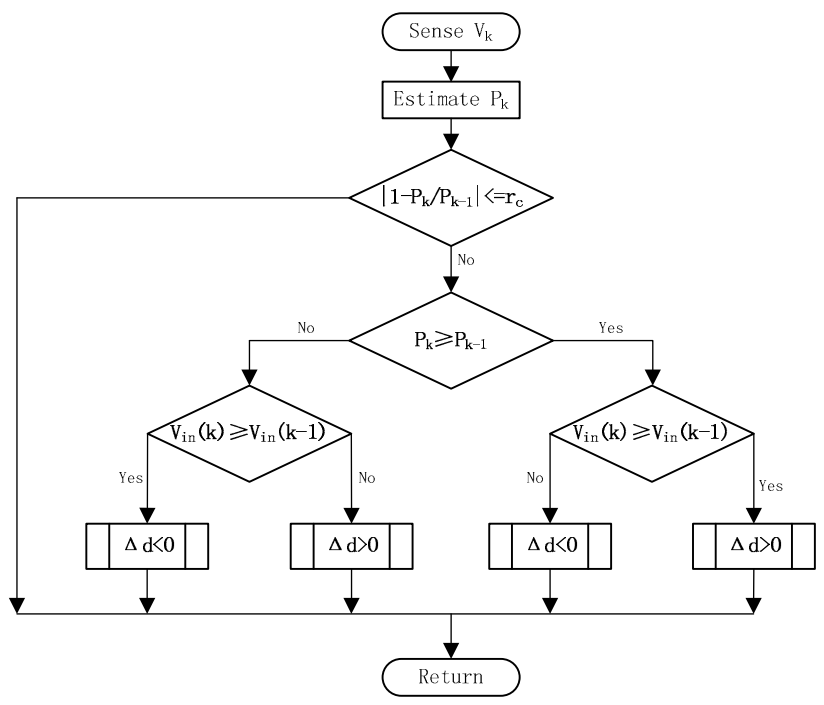

(b)

Fig. 5. The current-sensorless MPPT controller: (a) the schematic of the control algorithm; (b) the flowchart of the hill-climbing algorithm. used in this paper are $43.6 \mathrm{~V}$ and $5.3 \mathrm{~A}$, respectively; the switching period of the converter is $50 \mu \mathrm{s}$; the inductance is $400 \mu \mathrm{H}$; the resistance value $R$ is $330 \Omega$. Then the critical duty cycle can be derived by (12) and the value is 0.65 . Fig. 6 shows the inductor current $i_{1}$ for different duty cycles, the simulation result is consistent with the analysis where the current is continuous when $D=0.725$ and discontinuous when $D=0.6$. Fig. 7 shows the voltage regulation ratio as the function of the duty ratio for the quasi-double-boost converter, which is consistent with the results calculated from (15).

The solar radiation and temperature data provided by the NREL [9] is used to validate the proposed currentsensorless MPPT control for the PV system. The data was collected from the South Table Mountain site in Golden, Colorado, on May 31, 2010. During the simulation, the output power of the PV panel is estimated by the proposed current-sensorless MPPT algorithm (Fig. 5) and is compared with the measured output power by using both voltage and
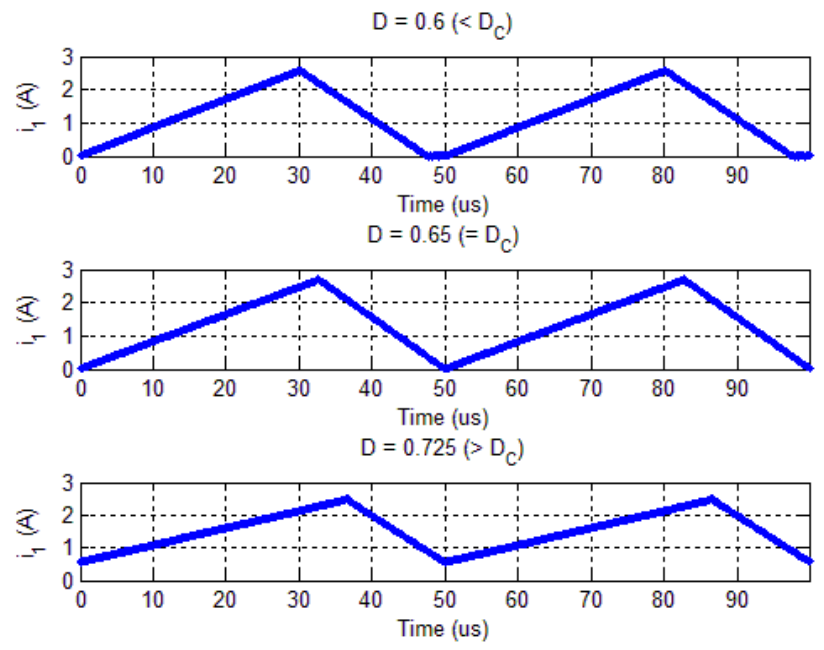

Fig. 6. The inductor current waveforms for different duty ratios.

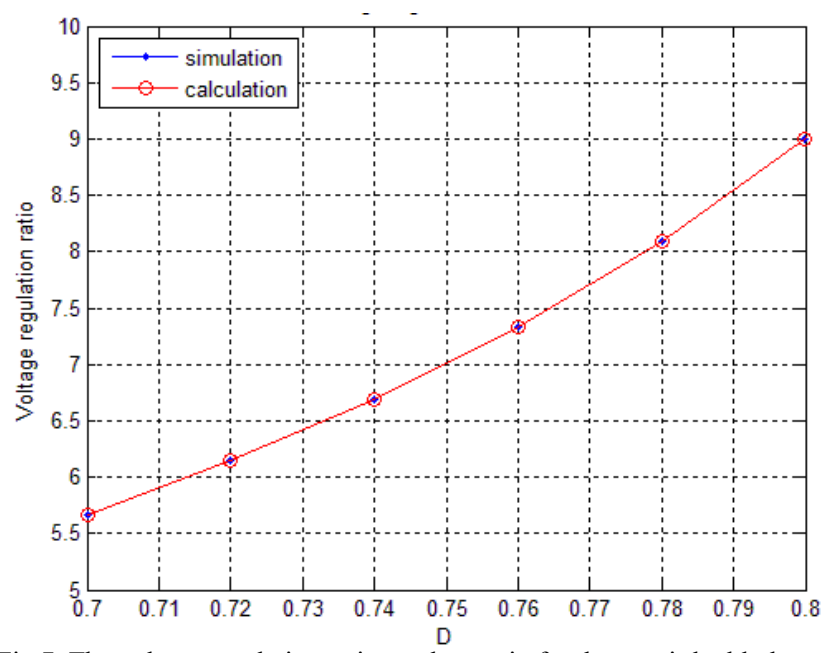

Fig.7. The voltage regulation ratio vs. duty ratio for the quasi-double-boost converter. 

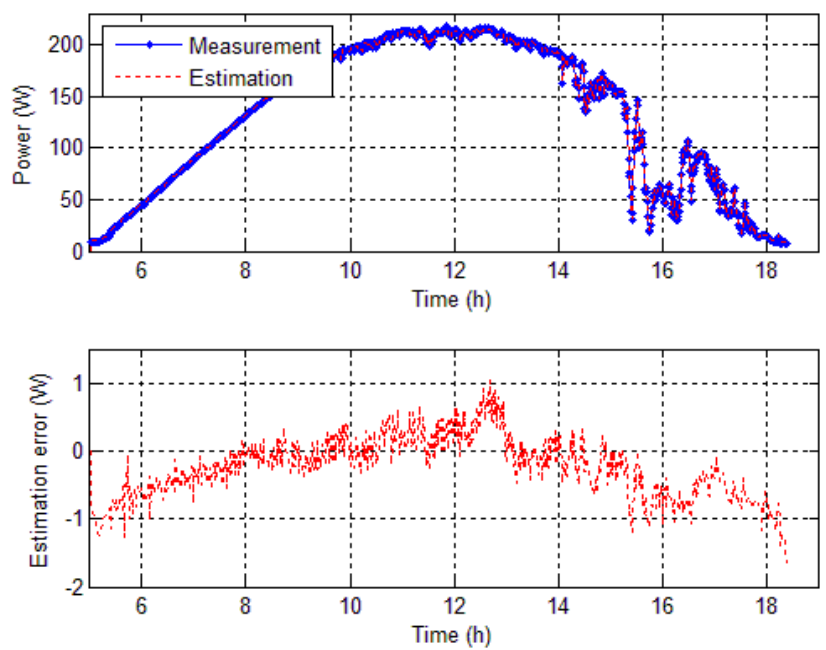

Fig. 8. The power estimation results.

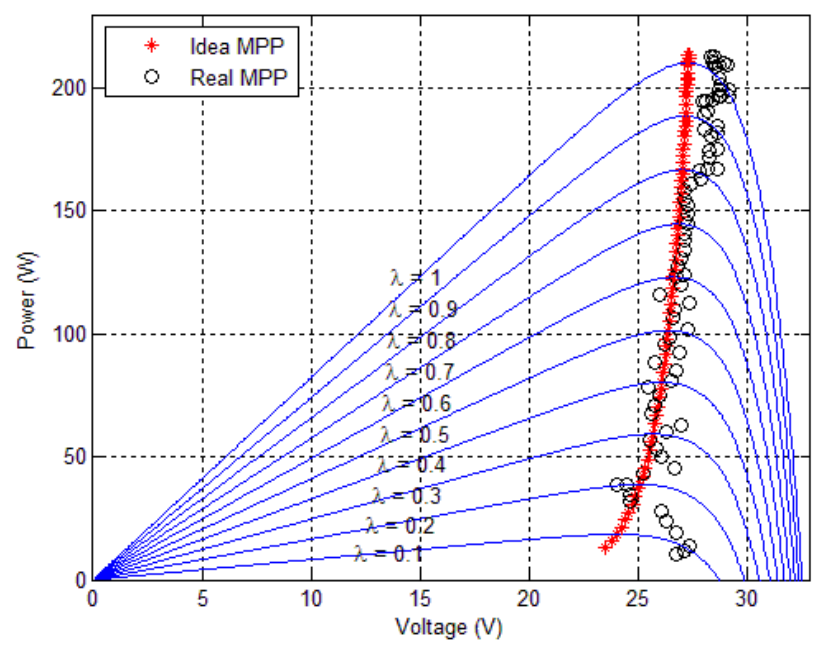

Fig. 9. The MPPT results of the PV system.

current sensors, as shown in the Fig. 8. The proposed current-sensorless algorithm estimates the real output power with good precision; the estimation errors are less than $1 \mathrm{~W}$ during most times of the day. Without knowing the information of solar radiation, the proposed MPPT algorithm controls the PV system to track the maximum power points (MPPs) by using the estimated current and measured voltage. Fig. 9 shows the operating points, i.e., the real MPPs, of the PV system at various solar radiation conditions during the day, which are close to ideal MPPs.

\section{EXPERIMENTAL RESULTS}

A quasi-double boost DC/DC converter was built and tested with a 175-W (the maximum output power) PV panel to validate the simulation. The prototype of the whole system is pictured in Fig. 10, which consists of the PV panels mounted on the roof of the authors' laboratory, the DC/DC converter, a sampling circuit, load resistors, and a computer with National Instruments LabVIEW, in which the MPPT

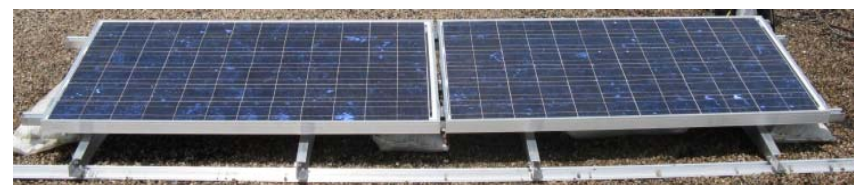

(a)

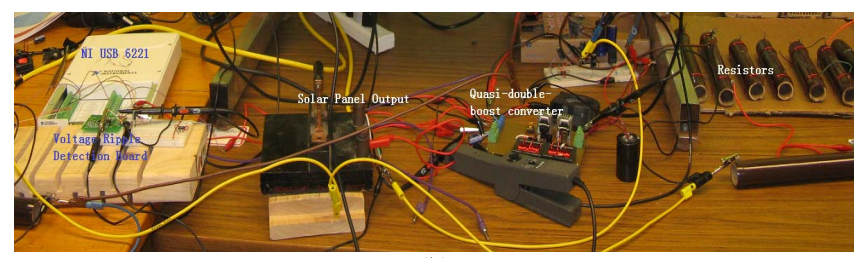

(b)

Fig. 10. The prototype of the whole system: (a) the PV panels; (b) the converter and testing equipment.

control algorithm was implemented. Two experiments were carried out to test the quasi-double-boost converter and current-sensorless MPPT control algorithm.

\section{A. Quasi-Double-Boost Converter}

As described by (11) and (15) the voltage regulation ratio is related with the circuit working mode. Therefore, it is necessary to test the system to verify the value of the voltage regulation ratio obtained from (11) and (15) as well as from simulations for different duty ratios. The system was tested by measuring the current of one inductor of the converter for different duty ratios. Fig. 11(a)-(c) shows the inductor current waveforms ( $\mathrm{C} 4$ in the figure) for three different duty ratios. It shows that the converter works in the critical mode when $D=0.65$ [Fig. 11(b)]. Besides, the converter works in DCM and CCM when $D=0.6$ [Fig. 11(a)] and 0.725 [Fig. 11(c)], respectively. These results are consistent with the simulation (see Fig. 6).

Fig. 12 compares the calculated curve of the voltage regulation ratio vs. duty ratio using (11) and (15) with that obtained from experiments. Since the calculation neglects the loss of components, such as inductors and switches, the calculated voltage regulation ratio is higher than the measured value at a given duty ratio. Particularly, as shown in Fig. 12, when the duty ratio is less than 0.65 , the measured ratio becomes closer to the calculated ratio. This is because when $D<0.65$, the converter achieves higher efficiency than that when $D>0.65$, as shown in Fig. 13. This relative higher efficiency helps the measured values approximate the theoretical values. The maximum power in Fig. 13 is derived when $D=0.75$, where the efficiency of the converter is higher than 90\%. Fig. 13 also indicates that when the converter extracts less power than the MPP, it is better to operate the converter at a point on the right side of the MPPs (the high-voltage side) of the I-V curves in Fig. 9 than the left side because of the high efficiency. This is obvious because the lower currents at the points on the right side of the MPPs result in less power loss than those on the left side.

\section{B. Current Sensorless MPPT}

The second experiment is to testify the effectiveness of the proposed current-sensorless MPPT. It utilizes the voltage 


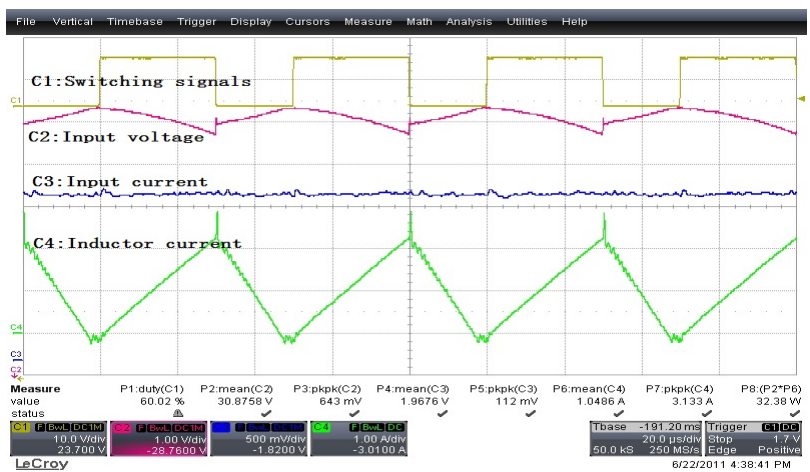

(a)

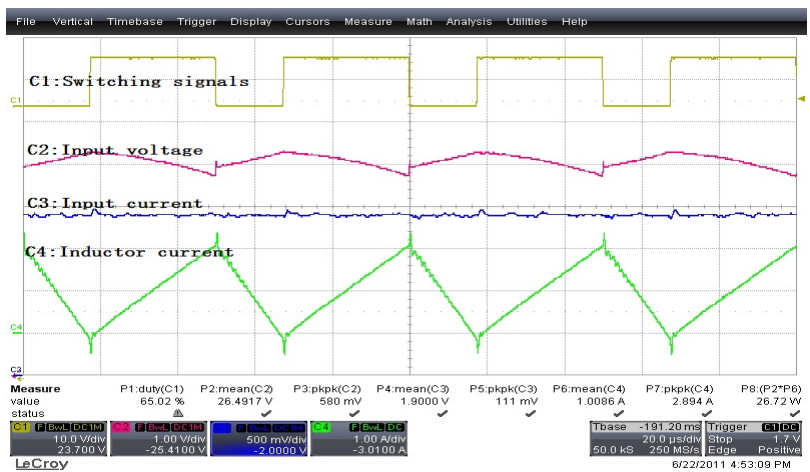

(b)

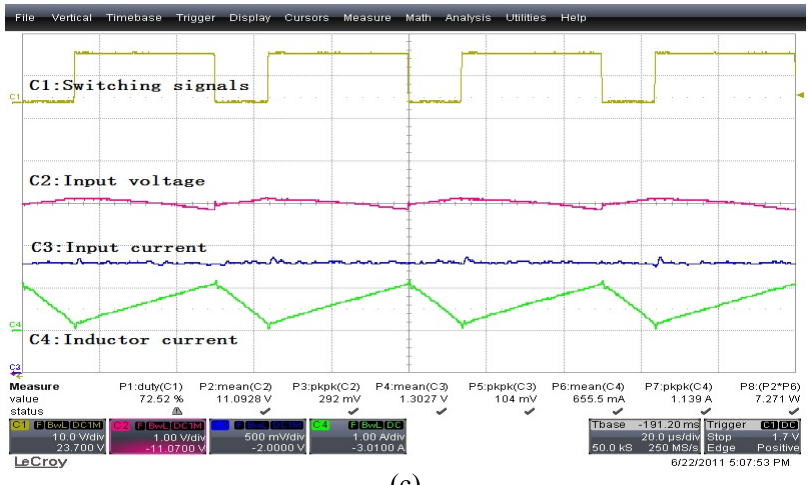

(c)

Fig. 11. The inductor current waveforms (C4): (a) $D=0.6$; (b) $D=$ $0.65 ;$ (c) $D=0.725$.

ripple of the input capacitor to calculate the input current of the converter with (18) and (19). Fig.14 shows the current estimation result, where the estimated value closely follows the actual current value. The maximum estimation error is less than $0.2 \mathrm{~A}$, which indicates that the maximum error of power estimation is less than $8 \mathrm{~W}$ for the converter.

Using the estimated current, the MPPT tracking performance in a high radiation condition is shown in Fig. 15. The initial duty ratio is set low so that the tracking begins from the high-voltage side of the P-V curve of the PV panel. The output power of the PV system continuously increases under the control of the current-sensorless MPPT algorithm. In the end, the output power reaches a value that is much higher than the initial value, as shown in Fig. 15. The

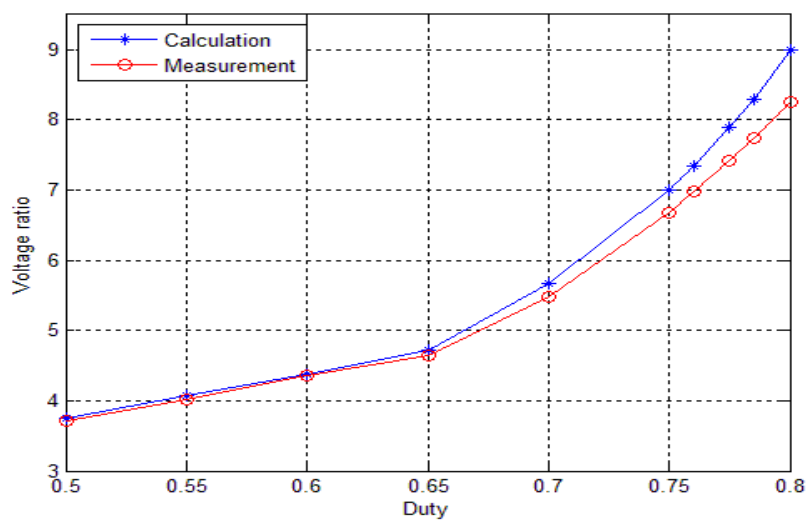

Fig. 12. The voltage regulation ratio vs. duty ratio.

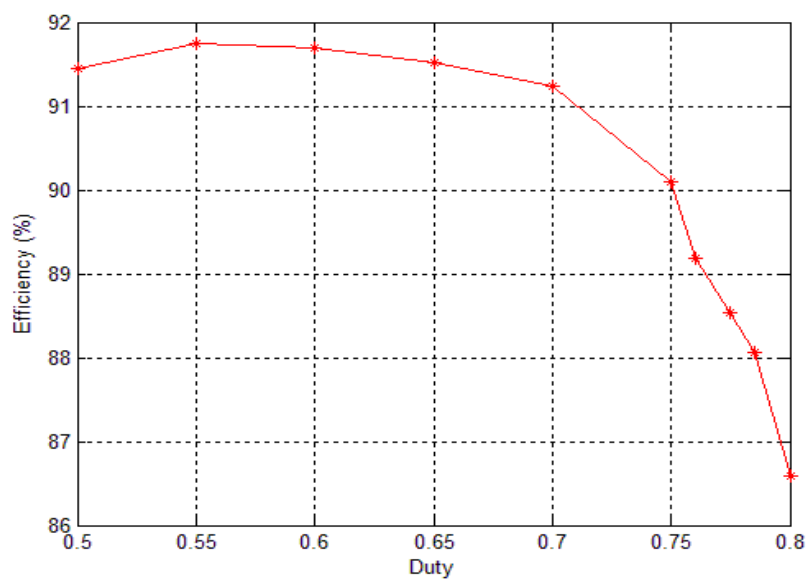

Fig. 13. The efficiency vs duty ratio

tracking trace which is indicated with the color bar also shows that the final operating point is close to the MPP. The small deviation from the P-V curve is largely due to the power estimation error (approximately $8 \mathrm{~W}$ ) and the slightly different measuring time, i.e., the P-V curve is derived 10 minutes after the MPPT in a clear day, which might cause the $\mathrm{P}-\mathrm{V}$ curve to change slightly from the time of performing the MPPT.

Fig. 16 compares the power output of a PV panel connected to a fixed load resistance through the quasidouble-boost converter with the MPPT control with a second identical PV panel connected directly to the same fixed load without the converter. This test was done in low radiation conditions to show the effectiveness of the system for all operating conditions. Fig. 16 shows that the output power of the PV panels with the MPPT system is much more than that without MPPT, which confirms the effectiveness of using the proposed sensorless MPPT system.

\section{CONCLUSION}

This paper has proposed a current-sensorless MPPT quasi-double-boost converter for PV systems, which works effectively to control the PV systems to operate at MPPs by only using a single voltage sensor. Simulation studies have 

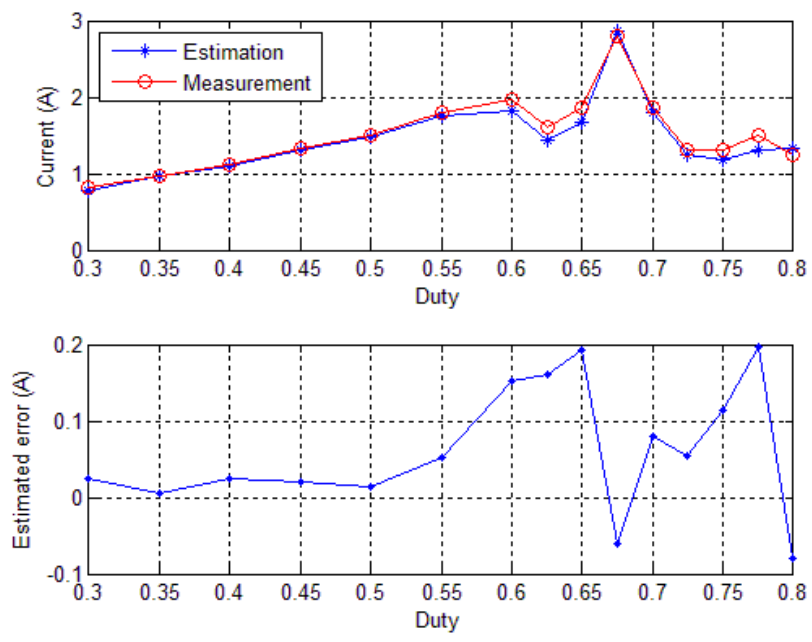

Fig. 14. Current estimation results.
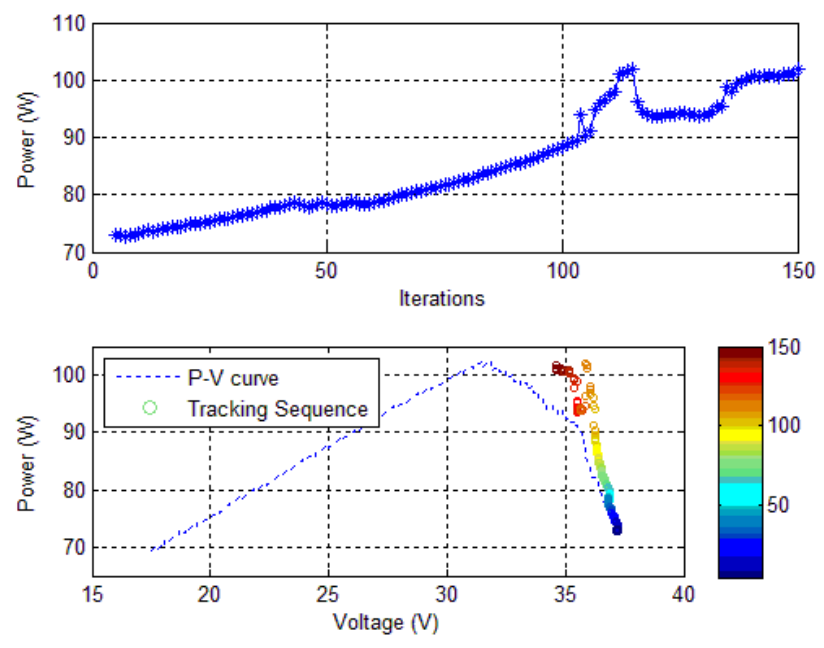

Fig. 15. The MPPT result in a high radiation condition.

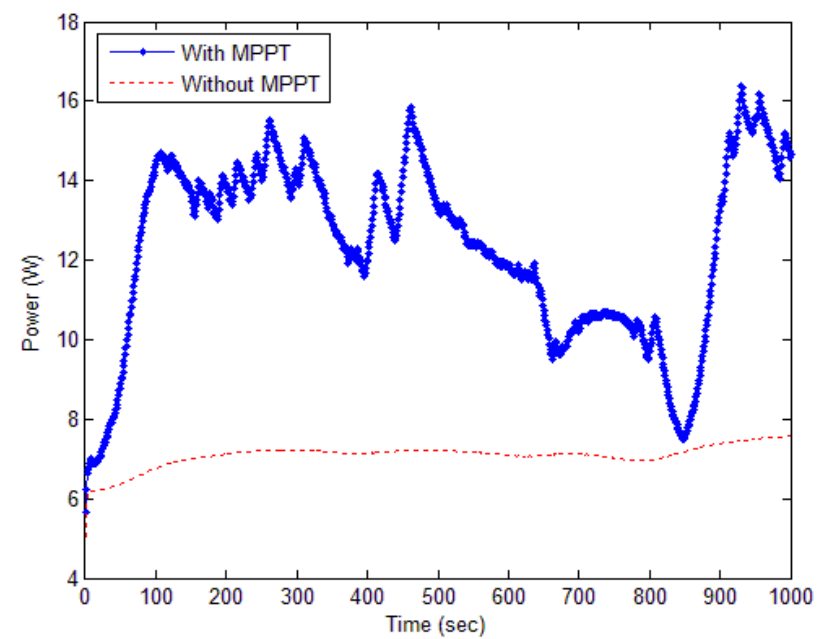

Fig. 16. The MPPT result in low radiation conditions. been performed in MATLAB Simulink by using real solar radiation data obtained from the NREL to validate the proposed system and algorithm. Experiments have been performed for a real PV system to further validate the proposed system and control algorithm; some concluding remarks have been obtained: 1) the voltage regulation ratio of the converter is not double the value of the basic boost converter as provided in [8]; 2) the current of the PV panel can be precisely estimated form the voltage ripple of the input capacitor of the DC/DC converter. The experiments also show that the proposed current-sensorless MPPT PV system is able to extract nearly maximum solar power. Although the derived current estimation algorithm is related to the converter topology, the thought of using voltage ripple to estimate current is applicable to other DC/DC converters as well.

\section{REFERENCES}

[1] V. Salas, E. Olias, A. Barrado, and A. Lazaro, "Review of the maximum power point tracking algorithms for stand-alone photovoltaic systems," Solar Energy Materials \& Solar Cells, vol. 90, no. 11 , pp. 1555-1578, July 2006.

[2] E. Koutroulis and K. Kalaitzakis, "Development of a microcontroller based photovoltaic maximum power point tracking control system," IEEE Trans. Power Electronics, vol. 16, pp. 46-54, Jan. 2001.

[3] C. Hua, J. Lin, and C. Shen, "Implementation of a DSP-controlled photovoltaic system with peak power tracking," IEEE Trans. on Industrial Electronics, vol. 45, no. 1, pp. 99-107, Feb. 1998.

[4] H. Hussein, I. Muta, T. Hoshino, and M. Osakada, "Maximum photovoltaic power tracking: an algorithm for rapidly changing atmospheric conditions," IEE Proceedings Generation, Transmission and Distribution, vol. 142, no. 1, pp. 59-64, Jan. 1995.

[5] C. Pan, J. Chen, C. Chu, and Y. Huang, "A fast maximum power point tracker for photovoltaic power systems," in Proc. 25th Annual Conference of the IEEE Industrial Electronics Society Conference, 1999, pp. 390-393.

[6] K. Itako and T. Mori, "A new current sensorless MPPT control method for PV generation systems," in Proc. 2005 European Conference on Power Electronics and Applications, pp. P.1-P.9.

[7] N. Kasa, T. Iida, and L. Chen, "Flyback inverter controlled by sensorless current MPPT for photovoltaic power system," IEEE Trans. on Industrial Electronics, vol. 52, no. 4, Aug. 2005.

[8] J. van Rensburg, M. Case, and D. Nicolae, "Double-boost DC to DC converter," in Proc. 34th Annual Conference of the IEEE Industrial Electronics Society, 2008, pp. 707-711.

[9] http://www.nrel.gov/midc/apps/go2url.pl?site=BMS\&page=day.pl?B MS. 